\title{
COULEUR DES PATTES ET DE LA CHAIR MORTALITÉ DANS UNE POPULATION DE VOLAILES
}

\author{
PAR \\ Ph. MERAT \\ Station de Recherches Avicoles, Jouy-en-Josas (S.-et-O.).
}

On ne sait pas avec précision si certains allèles déterminant la pigmentation des volailles, ou des gènes liés, peuvent influer sur le pourcentage global de survie dans les conditions ordinaires de l'élevage.

Sur plusieurs générations d'une population issue à l'origine d'un croisement, un certain nombre de familles de sœurs comportaient des poules à pattes jaunes $(w . w)$ et des poules à " pattes blanches " ou "roses " (WW ou Ww).

Dans ces familles, la mortalité comparée des poulettes de l'âge de 8 semaines au 3I décembre suivant, pour ces deux catégories, a été la suivante, en groupant les générations :

\begin{tabular}{|c|c|c|c|}
\hline \multicolumn{2}{|c|}{ Poules à pattes blanches } & \multicolumn{2}{|c|}{ Poules à pattes jaunes } \\
\hline $\begin{array}{l}\text { Poules vivantes } \\
\text { à } 8 \text { semaines }\end{array}$ & Mortalité (en \%) & $\begin{array}{l}\text { Poules vivantes } \\
\text { à } 8 \text { semaines }\end{array}$ & Mortalité (en \%) \\
\hline I 408 & 27,3 & 636 & 22,3 \\
\hline
\end{tabular}

Le pourcentage de survie est plus élevé chez les poulettes récessives (ఓఓœ), à pigmentation jaune des pattes et de la chair (différence proche du seuil I p. Ioo de signification). La tendance se répète assez bien dans chacune des générations étudiées.

Cette observation mérite d'être refaite sur d'autres populations, vu la signification économique du caractère "pigmentation des tarses ". Il serait intéressant de détailler la mortalité par causes, et de comparer les homozygotes dominants (WW) et les hétérozygotes. 